\title{
BALLISTIC EFFECTIVENESS OF SUPERDENSE SOLID COMPOSITE PROPELLANTS WITH ZIRCONIUM OR ZIRCONIUM HYDRIDE
}

\author{
D. Lempert, G. Manelis, and G. Nechiporenko \\ Institute of Problems of Chemical Physics \\ Russian Academy of Sciences \\ Av. Acad. Semenov 1, Chernogolovka 142432, Russia
}

\begin{abstract}
The ballistic effectiveness of propellants depends not only on the value of specific impulse but also on many other performances, primarily on the density. Despite the density itself does not enter the expression of the rocket velocity ( $W=I_{\mathrm{sp}} \ln \left(M_{\text {launch }} / M_{\text {finish }}\right)$ where $M_{\text {launch }}$ and $M_{\text {finish }}$ are the rocket launch mass and its mass after the propellant is burnt, respectively), it influences the value $M_{\text {launch }} / M_{\text {finish }}$ of the specific rocket. If one charges the construction of fixed volume with a more dense propellant, the ratio $M_{\text {launch }} / M_{\text {finish }}$ increases and, consequently, $W$ increases as well. In this paper, the possibility of creating solid composite propellants (SCP) with zirconium (density $6.49 \mathrm{~g} / \mathrm{cm}^{3}$ ) and zirconium hydride (density $5.61 \mathrm{~g} / \mathrm{cm}^{3}$ ) as energetic compounds instead of aluminum is considered. It was found for what kinds of engines these propellants have to be more effective than propellants based on aluminum.
\end{abstract}

\section{INTRODUCTION}

When developing new propellants, one has to consider in what kind of engines these propellants could be used. Besides the specific impulse $\left(I_{\mathrm{sp}}\right)$, the density is one of the most important factors defining ballistic effectiveness. The higher the $M_{\text {launch }} / M_{\text {finish }}$ ratio, the higher the density input.

It is possible to charge the same engine (that is the same propellant volume) with a propellant of lower $I_{\mathrm{sp}}$, but higher density. Therefore, it is possible to achieve the velocity growth for engines with the $M_{\text {finish }} / V_{\text {prop }}$ ratio ( $V_{\text {prop }}$ is the propellant volume) higher than the predefined value. For example, replacing aluminum by zirconium or its hydride, new propellants can be created with lower $I_{\mathrm{sp}}$ (at least, by $\left.20 \mathrm{~s}\right)$ but with a considerably higher density $\left(2.3 \mathrm{~g} / \mathrm{cm}^{3}\right.$ and higher) as compared with the formulations containing aluminum $\left(\sim 1.8 \mathrm{~g} / \mathrm{cm}^{3}\right)$.

This is an Open Access article distributed under the terms of the Creative Commons Attribution-Noncommercial License 3.0, which permits unrestricted use, distribution, and reproduction in any noncommercial medium, provided the original work is properly cited. 


\section{PROBLEM STATEMENT AND RESULTS}

If $\mathrm{Al}$ is replaced with $\mathrm{Zr}$ or $\mathrm{ZrH}_{2}$, the $I_{\mathrm{sp}}$ value always decreases, but the density grows considerably. The question arises: In what cases the $I_{\mathrm{sp}}$ loss can be compensated with the density growth? It is well known that the higher the value of $Z$ ( $Z=M_{\text {launch }} / M_{\text {finish }}$ where $M_{\text {finish }}$ is the total mass with no propellant), the higher the contribution of density to the maximum rocket velocity. For multistage space vehicles, the higher the stage, the lower the density contribution.

In this paper, the ballistic effectiveness of the SCP with $\mathrm{Zr}$ or $\mathrm{ZrH}_{2}$ is compared to that of the SCP with Al. Many different oxidizers and two binders have been considered as SCP compounds (Table 1). The $I_{\mathrm{sp}}$ values were calculated using the standard ASTRA and TERRA codes [1] at pressures of 40 and $1 \mathrm{~atm}$ in the combustion chamber and at the nozzle exit, respectively. For estimating the mutual influence of $I_{\mathrm{sp}}$ and density $(d)$ on the ballistic effectiveness, a new variable $I_{\text {ef }}$ (effective impulse) was introduced. Consider a reference rocket (index 0 ) with a definite ratio $F=V_{\text {prop }} / M_{\text {finish }}$ charged with the propellant possessing $I_{\mathrm{sp} 0}=251 \mathrm{~s}$ and $d_{0}=1.85 \mathrm{~g} / \mathrm{cm}^{3}$ (corresponds to the formulation $20 \% \mathrm{Al}$ $+9 \%$ standard hydrocarbon binder + ammonium perchlorate, $\left.Z_{0}=1+1.85 F\right)$. This engine would exhibit the value $W_{0}=g_{0} \cdot 251 \cdot \ln \left(Z_{0}\right)$. When charged with another propellant with $I_{\mathrm{sp} 2}$ and density $d_{2}$, the value of $Z$ for this engine changes

Table 1 Main properties of compounds $(\alpha=\mathrm{O} /[2 \mathrm{C}+0.5(\mathrm{H}-\mathrm{Cl})])$

\begin{tabular}{|c|c|c|c|c|}
\hline $\begin{array}{l}\text { Functional } \\
\text { purpose }\end{array}$ & Component & $\begin{array}{l}\Delta^{\circ} H_{f} \\
\mathrm{kcal} / \mathrm{kg}\end{array}$ & $\begin{array}{c}d, \\
\mathrm{~g} / \mathrm{cm}^{3}\end{array}$ & $\alpha$ \\
\hline \multirow{6}{*}{ Oxidizer } & Hydroxylammonium perchlorate (HAP) & -493 & 2.07 & 3.33 \\
\hline & Ammonium perchlorate (AP) & -593 & 1.95 & 2.7 \\
\hline & Ammonium dinitramine (ADN) & -270 & 1.82 & 2.0 \\
\hline & $\begin{array}{l}\text { Hyrazinium perchlorate semihydrate } \\
\text { (SHHP) } \mathrm{N}_{2} \mathrm{H}_{5} \mathrm{ClO}_{4} \cdot 1 / 2 \mathrm{H}_{2} \mathrm{O}\end{array}$ & -552 & 1.94 & 2.0 \\
\hline & Hydrazonium nitroformate (HNF) & -380 & 1.91 & 1.33 \\
\hline & HMX & 77 & 1.92 & 0.67 \\
\hline \multirow[b]{2}{*}{ Binder } & $\begin{array}{l}\text { Standard Hydrocarbon binder (SHCB) } \\
\mathrm{C}_{73.17} \mathrm{H}_{120.9}\end{array}$ & -93 & 0.92 & 0 \\
\hline & $\begin{array}{l}\text { Active binder }(\mathrm{AB}) \\
20 \% \text { polyvyniltetrazol, plasticized } \\
\text { with the mixture trinitroglycerole } \\
\text { and diazapentane } \\
\mathrm{C}_{18.96} \mathrm{H}_{34.64} \mathrm{~N}_{19.16} \mathrm{O}_{29.32}[2]\end{array}$ & -181 & 1.49 & 0.53 \\
\hline \multirow{3}{*}{$\begin{array}{l}\text { Energetic } \\
\text { compound }\end{array}$} & $\mathrm{Al}$ & 0 & 2.7 & 0 \\
\hline & $\mathrm{Zr}$ & 0 & 6.49 & 0 \\
\hline & $\mathrm{ZrH}_{2}$ & -455 & 5.61 & 0 \\
\hline
\end{tabular}


$\left(Z_{2}=1+d_{2}\left(Z_{0}-1\right) / 1.85\right)$, resulting in $W_{2}=g_{0} I_{\mathrm{sp} 2} \ln (Z)$. Then, the task is to calculate what $I_{\mathrm{sp}}$ value has to exhibit an SCP formulation with density $d_{0}$ for the same engine to reach velocity $W_{2}$. This $I_{\mathrm{sp}}$ value will be referred to as effective impulse $I_{\text {ef }}$. In Table 2 , different $Z_{0}$ values are

Table 2 The calculated $F$ values for the considered $Z_{0}$ values

\begin{tabular}{lc}
\hline$Z_{0}$ & $F, \mathrm{l} / \mathrm{kg}$ \\
\hline 1.5 & 0.27 \\
2 & 0.54 \\
2.5 & 0.81 \\
3 & 1.08 \\
3.5 & 1.35 \\
4 & 1.62 \\
5 & 2.16 \\
6 & 2.70 \\
8 & 3.78 \\
10 & 4.86 \\
\hline
\end{tabular}
considered together with the corresponding $F$ values: $F=\left(Z_{0}-1\right) / 1.85$.

Each formulation was assumed to contain $20 \%$ (vol.) binder (either SHCB or AB), because if the binder content is less, it is hard to form a propellant with acceptable rheological and physicomechanical properties. Aluminum content was varied from 16 up to $28 \%$ (mass.) whereas $\mathrm{Zr}$ and $\mathrm{ZrH}_{2}$ from 28 to $55 \%$ (mass.).

Figures 1 to 5 represent the calculated data for all formulations containing various combinations of oxidizers and binders with $Z_{0}$ values ranging from 1.5 to 3.5 (corresponding to different-purpose realistic rocket engines). In these figures, plotted along $Y$-axes is the increment of $I_{\mathrm{ef}}, \Delta I_{\mathrm{ef}}$, with respect to the basic formulation $\left(20 \% \mathrm{Al}+20 \%\right.$ (vol.) $\left.\mathrm{SHCB}+\mathrm{AP}, I_{\mathrm{sp}}=250.9 \mathrm{~s} ; d=1.85 \mathrm{~g} / \mathrm{cm}^{3}\right)$ while plotted along $X$-axes is the content of metal or hydride in the SCP formulation.

It is evident from Figs. 1 to 5 that the most of formulations with $\mathrm{Zr}$ or $\mathrm{ZrH}_{2}$ are more effective than the similar formulation with $\mathrm{Al}$, especially at low $Z_{0}$. First, consider how this advantage depends on $Z_{0}$ for the same oxidizer.

Formulations with HAP. This oxidizer is the most rich with oxygen $(\alpha$ $=3.33$ ). If $Z_{0}=1.5$, there is no considerable difference in using either SHCB or $\mathrm{AB}$ for both $\mathrm{Zr}$ and $\mathrm{ZrH}_{2} . \Delta I_{\text {ef }}$ achieves 30-35 s only due to replacing $\mathrm{Al}$ with $\mathrm{Zr}$ or $\mathrm{ZrH}_{2}$. If $Z_{0}=2.0, \Delta I_{\text {ef }}$ drops to $20-25$ s. If $Z_{0}$ further increases, the advantage of $\mathrm{ZrH}_{2}$ in comparison with $\mathrm{Zr}$ increases $\left(I_{\mathrm{sp}}\right.$ becomes more important than density). $\Delta I_{\text {ef }}$ achieves $10-12$ s at $Z_{0}=2.5$ and $5-8$ s at $Z_{0}=3.0$. At $Z_{0}=3.0, \Delta I_{\text {ef }}$ is already a few seconds only. In $\mathrm{Zr}+\mathrm{SHCB}+\mathrm{HAP}$ formulations, $\Delta I_{\text {ef }}$ rises to higher levels when $\mathrm{Zr}$ or $\mathrm{ZrH}_{2}$ content is about $50 \%$ (mass.) $\mathrm{Zr}$ (that is, about $67 \%$ of condensed phase in combustion products).

Formulations with AP have a bit lower $\Delta I_{\text {ef }}$ values (in comparison with formulations based on HAP) if they contain $\mathrm{Zr}$ or $\mathrm{ZrH}_{2}$ instead of $\mathrm{Al}$. The reason is oxygen deficit in AP in comparison with HAP. Anyway, $\Delta I_{\mathrm{ef}}$ values are rather high $\left(25-30,20,13-15,10\right.$, and $4-5$ s at $Z_{0}=1.5,2,2.5,3$, and 3.5 , respectively. In the $\mathrm{Zr}+\mathrm{SHCB}+\mathrm{AP}$ system, the maximum $I_{\mathrm{ef}}$ values are achieved at $\mathrm{Zr}$ or $\mathrm{ZrH}_{2}$ content $\sim 44 \%-45 \% \mathrm{Zr}$ (that is, $\sim 60 \%$ of condensed phase in combustion products).

Formulations with ADN. The advantage of AB over SHCB becomes more distinct. On the one hand, if $\mathrm{AB}$ is used, there is no difference between the $\Delta I_{\text {ef }}$ values for formulations with $\mathrm{Zr}$ and $\mathrm{ZrH}_{2}$ while in the formulations based 


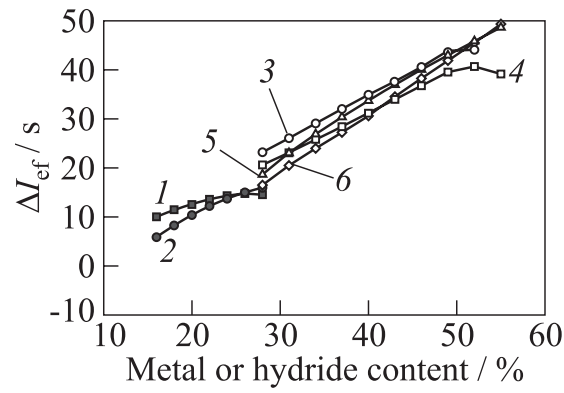

(a)

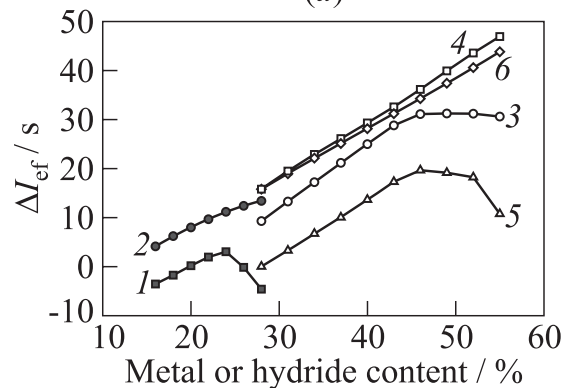

(c)

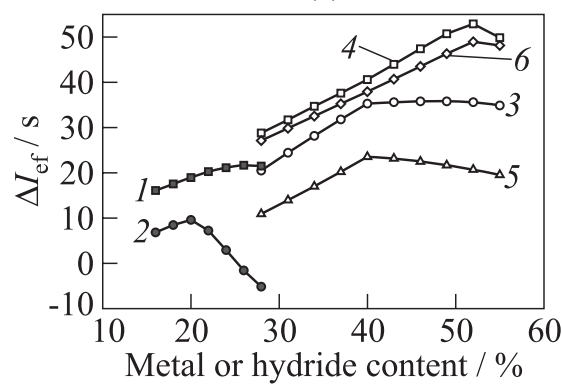

(e)

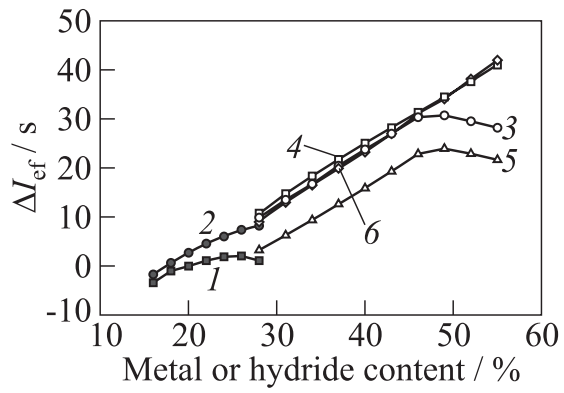

(b)

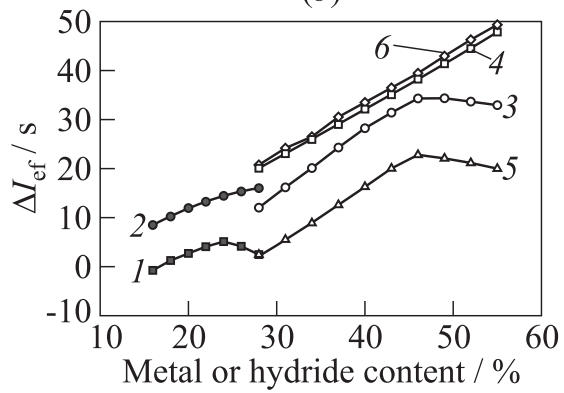

(d)

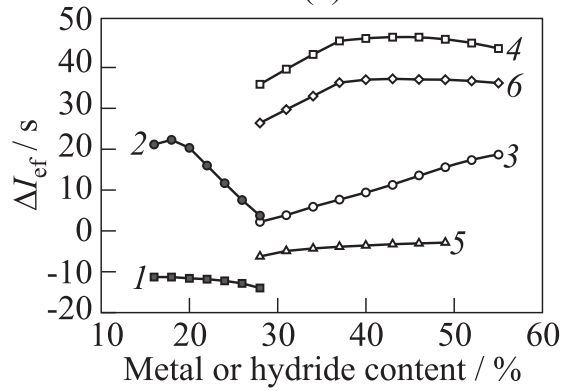

$(f)$

Figure 1 Values of $\Delta I_{\mathrm{ef}}$ for $Z_{0}=1.5(F=0.27): 1-\mathrm{Al}+\mathrm{SHCB}+$ oxidizer; $2-\mathrm{Al}+\mathrm{AB}+$ oxidizer; $3-\mathrm{Zr}+\mathrm{SHCB}+$ oxidizer; $4-\mathrm{Zr}+\mathrm{AB}+$ oxidizer; $5-\mathrm{ZrH}_{2}+\mathrm{SHCB}+$ oxidizer; and $6-\mathrm{ZrH}_{2}+\mathrm{AB}+$ oxidizer for different oxidizers: (a) HAP; (b) AP; (c) ADN; (d) SHHP; $(e) \mathrm{HNF}$; and $(f) \mathrm{HMX}$

on HAP, the advantage of $\mathrm{ZrH}_{2}$ over $\mathrm{Zr}$ increases with the $Z_{0}$. On the other hand, in the formulations with $\mathrm{ADN}$, the effectiveness of aluminum replacement with $\mathrm{Zr}$ or $\mathrm{ZrH}_{2}$ is almost the same as in the formulations with HAP and AP (30, $20,12-13,7-8$, and $4-5 \mathrm{~s}$ at $Z_{0}=1.5,2,2.5,3$, and 3.5 , respectively). In the $\mathrm{Zr}+\mathrm{SHCB}+\mathrm{ADN}$ system, the maximum $I_{\mathrm{ef}}$ values are achieved at $\mathrm{Zr}$ content $45 \%-47 \%$ (that is, $60 \%-62 \%$ of condensed phase in combustion products). 

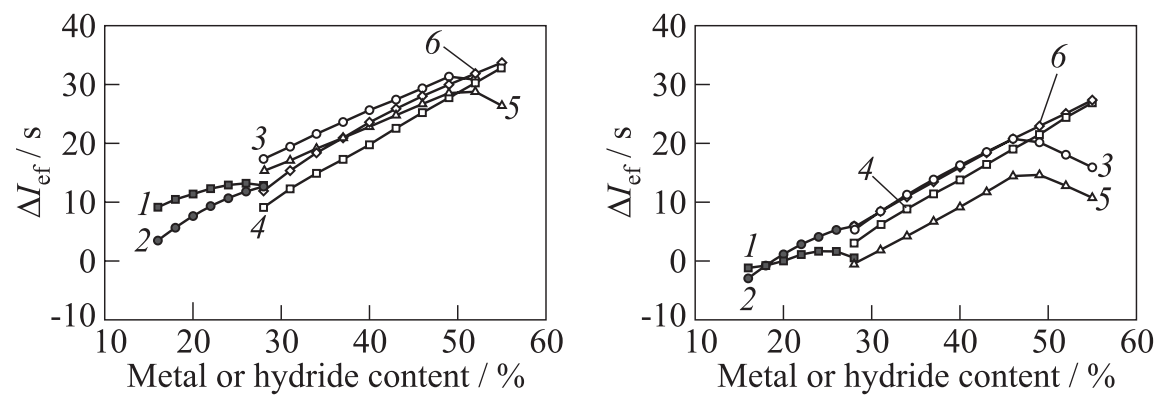

(a)

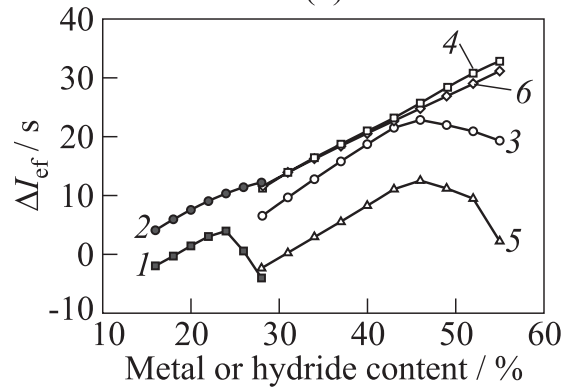

(b)

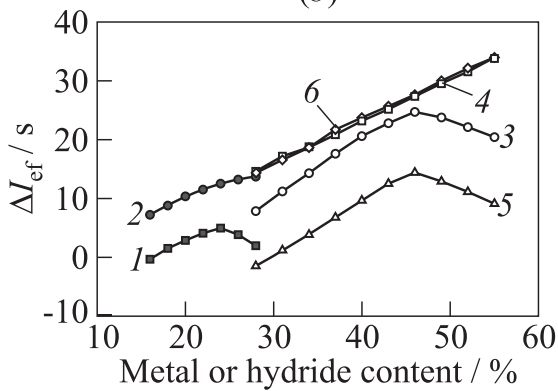

(c)

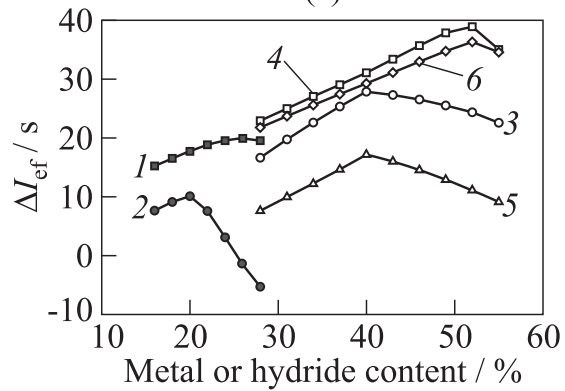

(e)

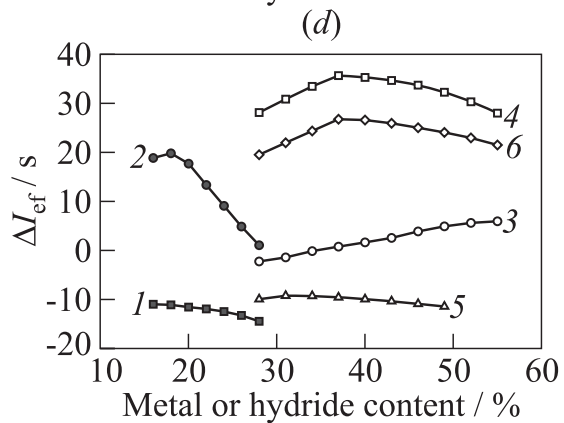

$(f)$

Figure 2 Values of $\Delta I_{\text {ef }}$ for $Z_{0}=2.0(F=0.54)$. See Fig. 1 for details

Formulations with SHHP. Here, the $I_{\mathrm{ef}}$ gain is almost the same as with ADN. Only the formulations with $\mathrm{ZrH}_{2}$ and with SHCB are not effective enough. If $Z_{0}=1.5, I_{\mathrm{sp}}$ gain is $30 \mathrm{~s}(\mathrm{Zr}$ and $\mathrm{AB})$ and $20 \mathrm{~s}$ ( $\mathrm{Zr}$ and $\left.\mathrm{SHCB}\right)$; if $Z_{0}=2$, the gain is $\sim 20 \mathrm{~s}(\mathrm{Zr}$ and $\mathrm{AB})$ and $15 \mathrm{~s}(\mathrm{Zr}$ and $\mathrm{SHCB})$; if $Z_{0}=2.5$, the gain is $\sim 15 \mathrm{~s}(\mathrm{Zr}$ and $\mathrm{AB})$ and $5 \mathrm{~s}$ ( $\mathrm{Zr}$ and $\mathrm{SHCB})$; if $Z_{0}=3$, the gain is $\sim 7-8 \mathrm{~s}$ ( $\mathrm{Zr}$ and $\mathrm{AB}$ ), if $Z_{0}=3.5$, there is only a small gain for the formulations with $\mathrm{Zr}$ and $\mathrm{AB} . \mathrm{Zr}+\mathrm{SHCB}+\mathrm{SHHP}$ formulations achieve the maximum $I_{\mathrm{ef}}$ values at $45 \%-47 \% \mathrm{Zr}$ or $\mathrm{ZrH}_{2}$ (that is, $60 \%-62 \%$ of condensed phase in combustion products). In the formulations with $\mathrm{Zr}$ and $\mathrm{AB}, I_{\text {ef }}$ continues increasing with 

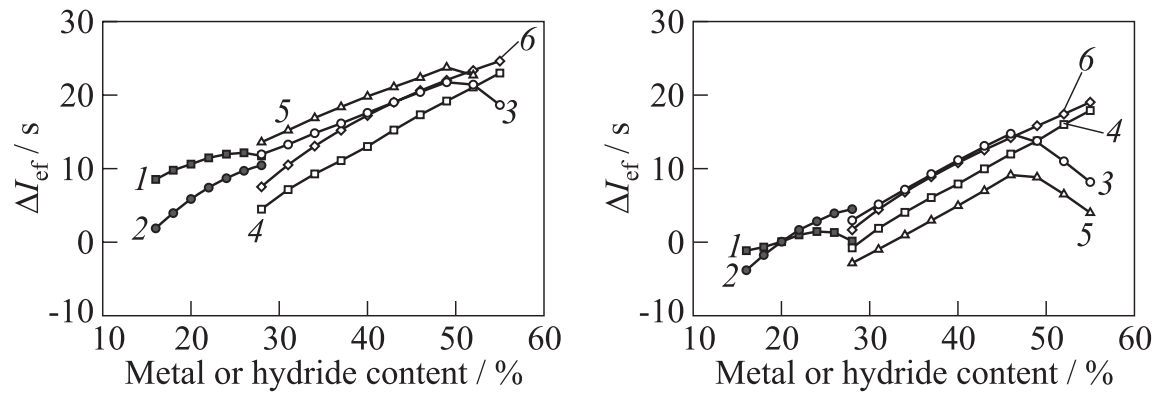

(a)

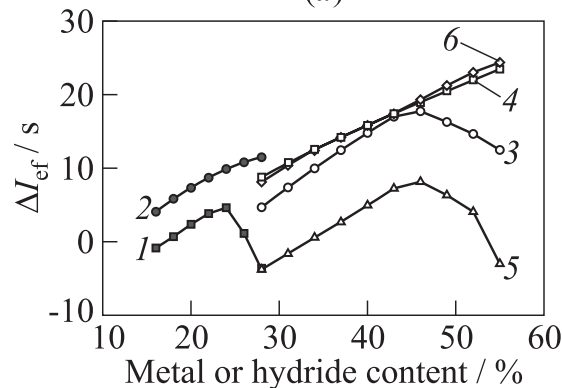

(b)

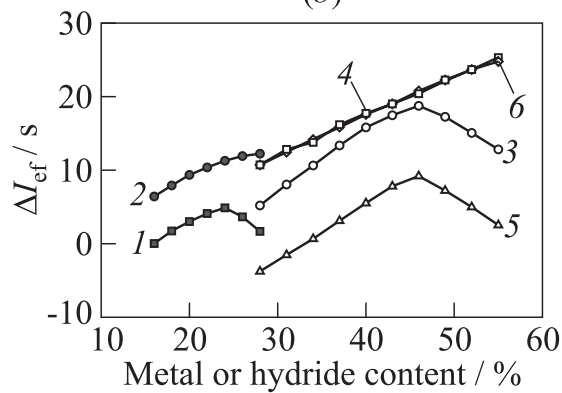

(c)

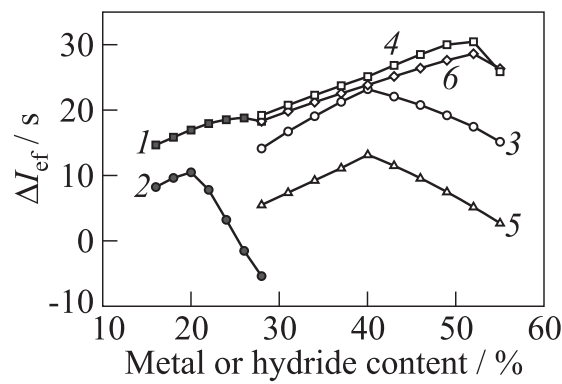

(e)

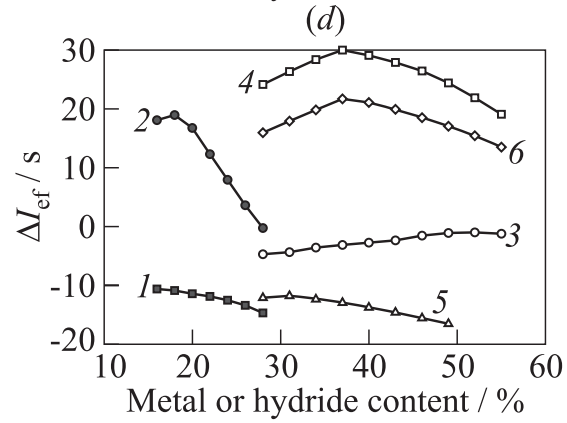

(f)

Figure 3 Values of $\Delta I_{\text {ef }}$ for $Z_{0}=2.5(F=0.81)$. See Fig. 1 for details

the $\mathrm{Zr}$ content up to $70 \% \mathrm{ZrH}_{2}$. The same effect relates to similar formulations based on HAP, AP, and ADN oxidizers.

Formulations with HNF. If $Z_{0}=1.5$, the gain is $30 \mathrm{~s}(\mathrm{Zr}$ and $\mathrm{AB})$; if $Z_{0}=2.0$, it is $\sim 20 \mathrm{~s}$; if $Z_{0}=2.5$, it is $10-12 \mathrm{~s}$; and if $Z_{0}=3.0$, it is $5-8 \mathrm{~s}$. All formulations with $\mathrm{AB}$ are better than those with SHCB.

Formulations with HMX. This oxidizer differs considerably from all other oxidizers because HMX has the lowest value of $\alpha$. Therefore, the formulations with SHCB are of no interest at all: they are far worse than the formulations 


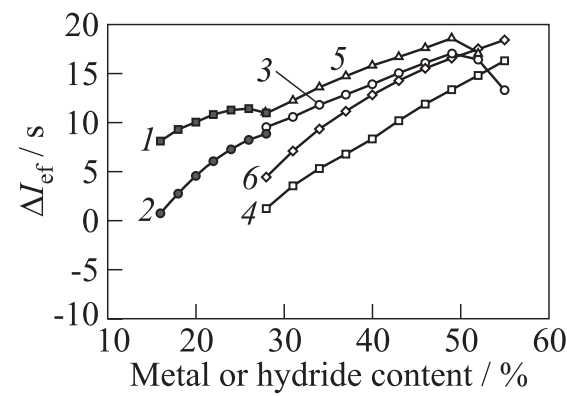

(a)

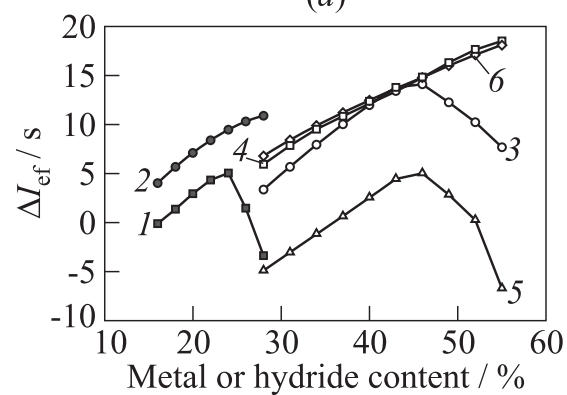

(c)

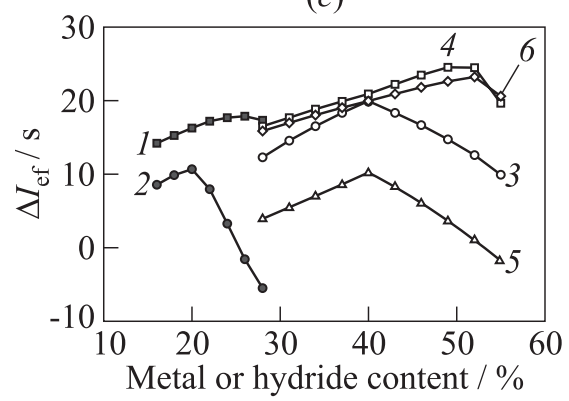

(e)

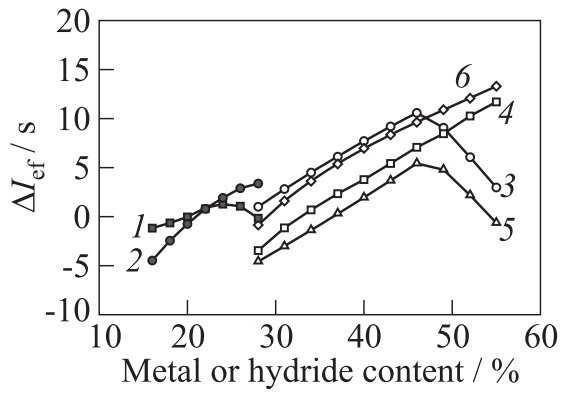

(b)

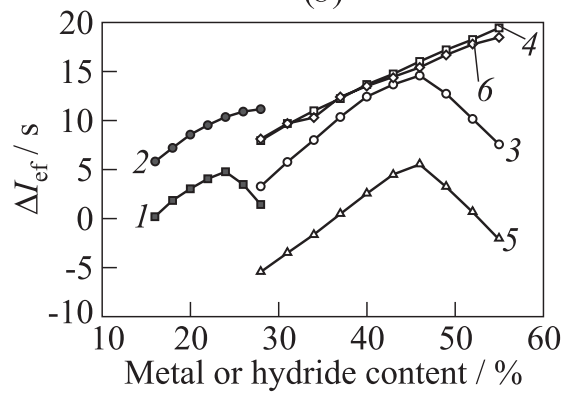

(d)

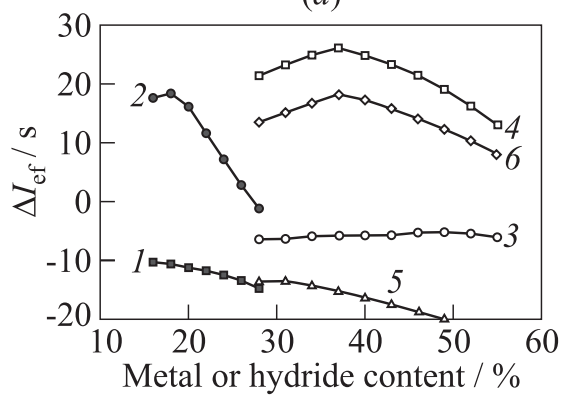

$(f)$

Figure 4 Values of $\Delta I_{\text {ef }}$ for $Z_{0}=3.0(F=1.08)$. See Fig. 1 for details

with $\mathrm{AB}$. The formulations with $\mathrm{AB}$ and $\mathrm{Zr}$ are considerably better than the formulations with $\mathrm{AB}$ and $\mathrm{ZrH}_{2}$ for all values of $Z_{0}$. If $Z_{0}=1.5$, the $I_{\text {ef }}$ gain is $15-20 \mathrm{~s}\left(\mathrm{Zr}\right.$ and $\left.\mathrm{ZrH}_{2}\right)$; if $Z_{0}=2.0$, the formulations with $\mathrm{AB}$ and $\mathrm{Zr}$ win $15 \mathrm{~s}$ while the formulations with $\mathrm{AB}$ and $\mathrm{ZrH}_{2}$ win $7 \mathrm{~s}$. If $Z_{0}=2.5$, the $I_{\text {ef }}$ gain is $10 \mathrm{~s}(\mathrm{Zr})$ and a few seconds only for $\mathrm{ZrH}_{2}$. If $Z_{0}=3$, there is a gain of $7 \mathrm{~s}$ for the formulations with $\mathrm{Zr}$ and $\mathrm{AB}$ and no gain for $\mathrm{ZrH}_{2}$. In the $\mathrm{Zr}+\mathrm{SHCB}+\mathrm{HMX}$ system, the maximum $I_{\text {ef }}$ values are achieved at $\mathrm{Zr}$ or $\mathrm{ZrH}_{2}$ content of $38 \%-41 \%$ (that is, $52 \%-55 \% \mathrm{ZrO}_{2}$ in combustion products). 


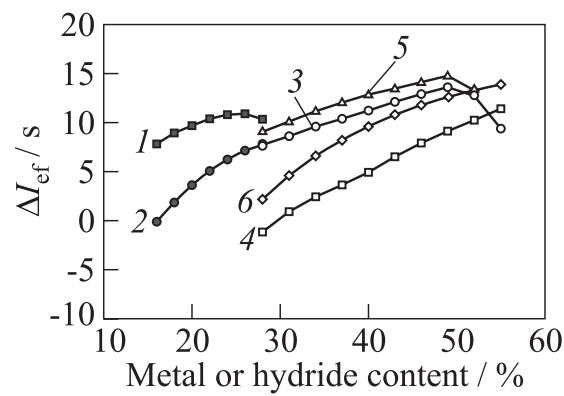

(a)

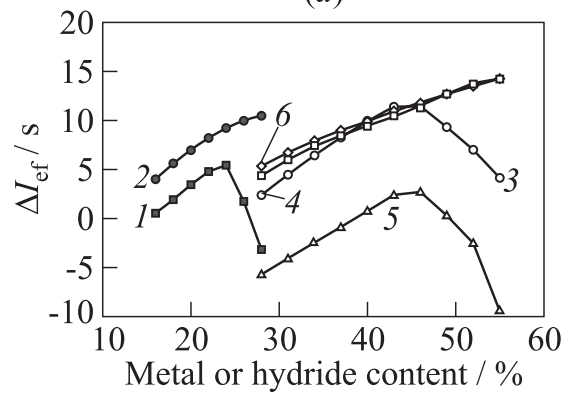

(c)

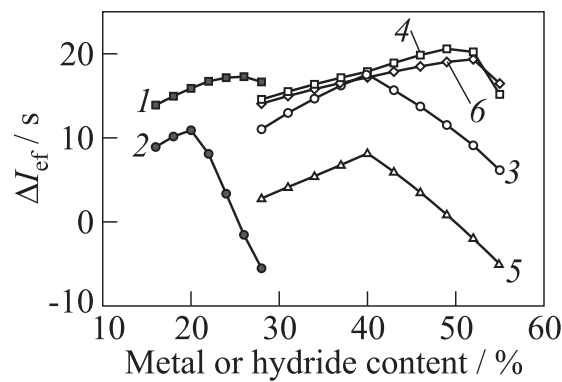

(e)

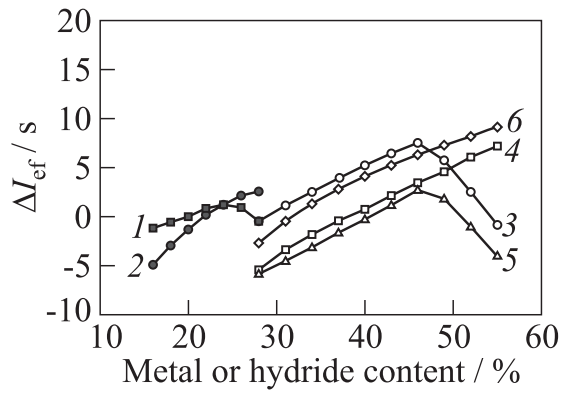

(b)

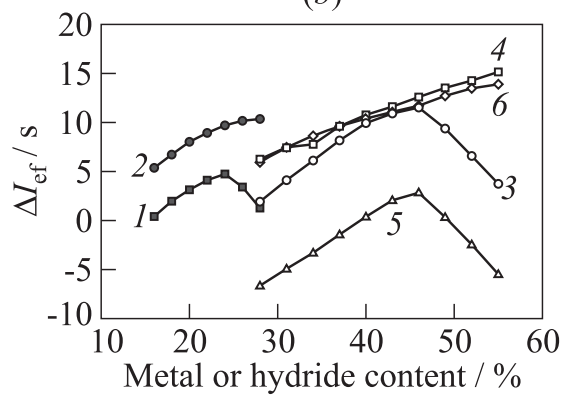

(d)

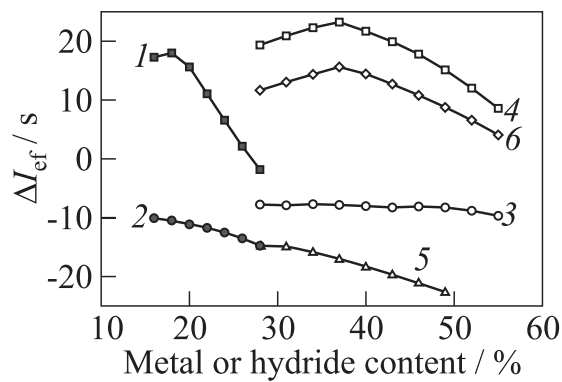

(f)

Figure 5 Values of $\Delta I_{\text {ef }}$ for $Z_{0}=3.5(F=1.35)$. See Fig. 1 for details

When comparing the formulations with different oxidizers, a particular regularity can be noticed for oxidizers with high oxygen content ( $\alpha \geq 2.0$ : HAP, AP, $\mathrm{ADN}$, and SHHP). As a matter of fact, $I_{\text {ef }}$ increases with the $\mathrm{Zr}$ or $\mathrm{ZrH}_{2}$ content in the formulations with $\mathrm{AB}$, while in similar formulations based on the oxidizers with lower $\alpha$ (HNF or HMX), there is a maximum at $\mathrm{Zr}$ or $\mathrm{ZrH}_{2}$ content, corresponding $\sim 70 \%$ and $50 \%$ of $\mathrm{ZrO}_{2}$ for $\mathrm{HNF}$ and $\mathrm{HMX}$, respectively.

Therefore, the oxidizers with lower $\alpha$ values require replacing SHCB with AB and the gain due to using a Zr-containing energetic compound instead of $\mathrm{Al}$ is 


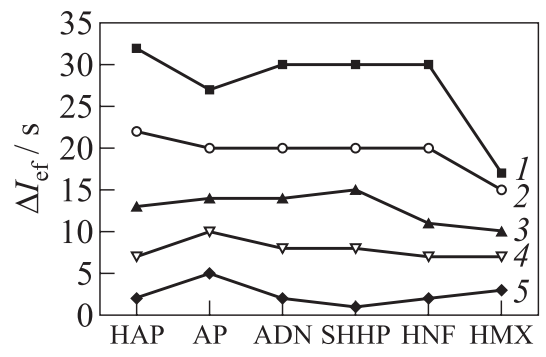

Figure 6 Maximum $\Delta I_{\text {ef }}$ values due to replacing of $\mathrm{Al}$ with $\mathrm{Zr}$ or $\mathrm{ZrH}_{2}$ in the formulations based on different oxidizers for different $Z_{0}: 1-1.5 ; 2-2.0 ; 3-2.5$; $4-3.0$; and $5-3.5$

getting higher if $\mathrm{Zr}$ rather than $\mathrm{ZrH}_{2}$ is used. All said above is illustrated in Fig. 6.

It should be noticed additionally that the formulations with $\mathrm{Zr}$ and $\mathrm{AB}$ exhibit very high combustion temperatures $\left(T_{\mathrm{c}}\right)$. If $\mathrm{ZrO}_{2}$ content in combustion products reaches $50 \%, T_{\mathrm{c}}$ is already higher than $3700-3800 \mathrm{~K}$; if $\mathrm{ZrO}_{2}$ content in combustion products reaches $65 \%-70 \%$ (that is, when $I_{\text {ef }}$ attains the maximum value), the $T_{\mathrm{c}}$ values become $4000 \mathrm{~K}$ and even higher (Fig. 7). The fact that the formulations with $\mathrm{Al}$ exhibit lower $T_{\mathrm{c}}$ values than the formulations with $\mathrm{Zr}$ (though the heat of formation of $1 \mathrm{~g} \mathrm{Al}_{2} \mathrm{O}_{3}$ is about twice higher than the heat of formation of $1 \mathrm{~g} \mathrm{ZrO}_{2}$ ) has a simple explanation. First, the compositions with a high content of condensed phase in combustion products (in Zr-containing compositions, this value is about twice higher than in Al-containing compositions) exhibit higher $T_{\mathrm{c}}$ because the specific (per $1 \mathrm{~g}$ ) heats of condensed products are considerably smaller than the specific heats of gases (particularly, $\mathrm{H}_{2} \mathrm{O}$ and $\mathrm{H}_{2}$ ). Besides, the specific heat of solid $\mathrm{ZrO}_{2}$ is almost twice lower than that of solid $\mathrm{Al}_{2} \mathrm{O}_{3}$. Second, at temperatures exceeding $3600 \mathrm{~K}, \mathrm{ZrO}_{2}$ dissociates to a considerably less extent than $\mathrm{Al}_{2} \mathrm{O}_{3}$, and for $\mathrm{Al}_{2} \mathrm{O}_{3}$ dissociation, a rather high amount of heat is consumed. For example, for heating a system with the gross formula $\mathrm{ZrO}_{2}$ from 3600 up to $4000 \mathrm{~K}$, the needed amount of heat is a factor of 3 less than that needed to heat $\mathrm{Al}_{2} \mathrm{O}_{3}$, other conditions being equal.

Unlike the compositions with $\mathrm{Zr}$ and $\mathrm{AB}$, the formulations with $\mathrm{ZrH}_{2}$ and $\mathrm{AB}$ have rather acceptable $T_{\mathrm{c}}$ values (not higher than $3800 \mathrm{~K}$ for all oxidizers except HAP) because these formulations contain more hydrogen and have a bit lower $\Delta^{\circ} H_{f}$. The formulations with $\mathrm{Zr}$ and SHCB have considerably lower $T_{\mathrm{c}}$ values than those with $\mathrm{Zr}$ and $\mathrm{AB}$, and these $T_{\mathrm{c}}$ values are also quite acceptable. The compositions with $\mathrm{HMX}, \mathrm{ZrH}_{2}$, and $\mathrm{SHCB}$ show too small $T_{\mathrm{c}}$ values.

Compare now the ballistic properties of compositions with all oxidizers under consideration at different values of $Z_{0}$. The task is to find the best formulations for different engines with different $Z_{0}$ or $F$ values. As the baseline 

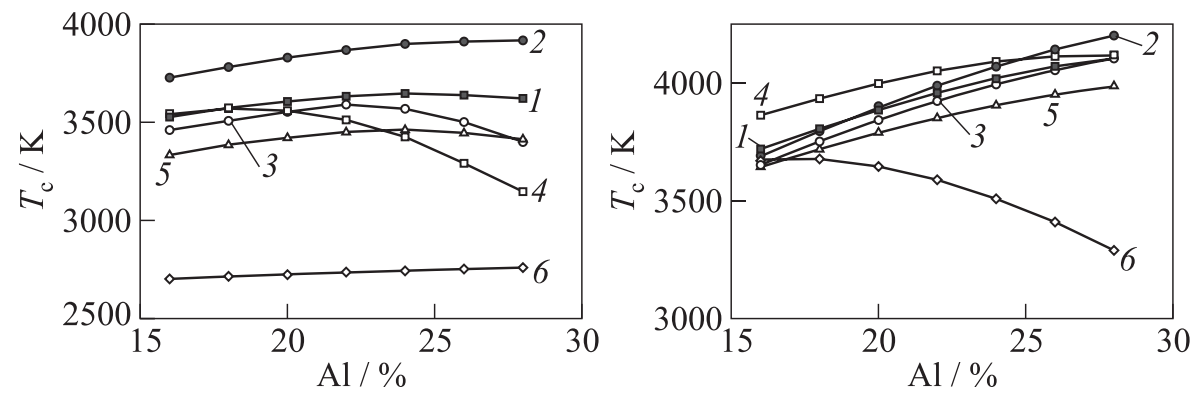

(a)
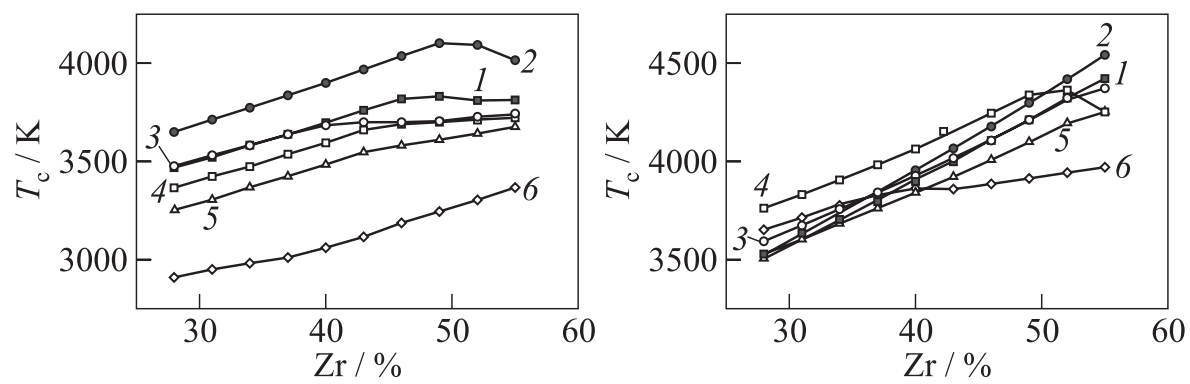

(b)
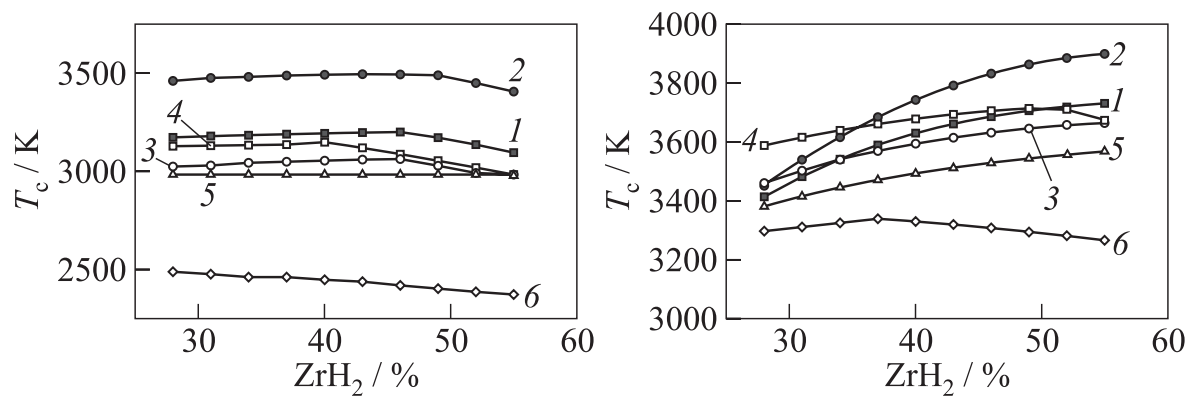

(c)

Figure 7 Values of $T_{\mathrm{c}}$ for formulations with different oxidizers $(1-\mathrm{AP} ; 2-\mathrm{HAP}$; 3 - ADN; $4-\mathrm{HNF}$; 5 - SHHP; and 6- HMX), energetic components ( $(a) \mathrm{Al}$; (b) $\mathrm{Zr}$; and $(c) \mathrm{ZrH}_{2}$ ), and binder (SHCB - left column or $\mathrm{AB}$ - right column, both $20 \%$ (vol.))

formulation, the above-mentioned $20 \% \mathrm{Al}+20 \%$ (vol.) $\mathrm{SHCB}+\mathrm{AP}$ system is still considered.

The brief conclusions on the relative effectiveness of the formulations under investigation are: 
$Z_{0}=1.5(F=0.27)$. The formulations with HAP show the maximum gain $\Delta I_{\mathrm{ef}}=40-47 \mathrm{~s}$ for $\mathrm{Zr}$ and $\mathrm{ZrH}_{2} ; \mathrm{ZrH}_{2}$ is a bit better than $\mathrm{Zr}$. The formulations with $\mathrm{AB}$ are a bit better than those with $\mathrm{SHCB}$ (if $T_{\mathrm{c}}$ values are not considered). The lower the value of $\alpha$ in the oxidizer, the higher the difference between the effectiveness of formulations based on $\mathrm{AB}$ and SHCB, that is, the lower the $\alpha$, the worse are the formulations with SHCB. Then, the lower the $\alpha$, the higher the gain of $\mathrm{Zr}$ over $\mathrm{ZrH}_{2}$. The formulations with $\mathrm{Zr}$ and $\mathrm{AB}$ are capable of ahieving $\Delta I_{\mathrm{ef}}$ of about $40-45 \mathrm{~s}$ as compared with the baseline formulation. Using the formulation with $\mathrm{Zr}$ and SHCB, the gain depends much on the oxidizer nature: 40-43 s for HAP, 22-30 s for AP, 25-31 s for ADN, $28 \mathrm{~s}$ for SHHP, 30-35 s for HNF, and only for HMX, the gain is at least $\sim 15 \mathrm{~s}$.

$Z_{0}=2(F=0.54)$. All oxidizers in the formulations with $\mathrm{AB}$ show the $I_{\mathrm{ef}}$ gain up to $35 \mathrm{~s}$. The formulations with SHCB continue to loose the effectiveness, particularly, with $\mathrm{ZrH}_{2}$.

$Z_{0}=2.5(F=0.81)$. The $I_{\text {ef }}$ gain is up to $21-23 \mathrm{~s}$ with HAP, $15-18 \mathrm{~s}$ with AP, $30 \mathrm{~s}$ with HNF, 23-24 s with ADN, 24-25 s with SHHP, $30 \mathrm{~s}$ (Zr), and $20 \mathrm{~s}$ $\left(\mathrm{ZrH}_{2}\right)$ with HMX.

$Z_{0}=3(F=1.08)$. In the formulations with $\mathrm{AB}$, the $I_{\mathrm{ef}}$ gain is up to $30 \mathrm{~s}$ with HNF, 22-23 s with ADN, 15-20 s with HAP, $25 \mathrm{~s}$ with SHHP, $22 \mathrm{~s}$ with $\mathrm{AP}$, and $30 \mathrm{~s}(\mathrm{Zr})$ or $22 \mathrm{~s}\left(\mathrm{ZrH}_{2}\right)$ with HMX.

$Z_{0}=3.5(F=1.35)$. The $I_{\text {ef }}$ gain is up to $17-20 \mathrm{~s}$ with ADN, $17-18 \mathrm{~s}$ with HAP, 17-19 s with SHHP, 12-13 s with AP, 23-25 s with HNF, $25 \mathrm{~s}(\mathrm{AB}+\mathrm{Zr})$, and $17 \mathrm{~s}\left(\mathrm{AB}+\mathrm{ZrH}_{2}\right)$ with $\mathrm{HMX}$.

Thus, the replacement of $\mathrm{Al}$ with $\mathrm{Zr}$ or $\mathrm{ZrH}_{2}$ only (if the best formulation in each kind of composition is considered) with the best binder (for Al-containing as well as for Zr-containing formulations) allows obtaining the $I_{\mathrm{ef}}$ gain of $30 \mathrm{~s}$ at $Z_{0}=1.5 ; \sim 20 \mathrm{~s}$ at $Z_{0}=2 ; 13-14 \mathrm{~s}$ at $Z_{0}=2.5 ; 8 \mathrm{~s}$ at $Z_{0}=3$, and $\sim 5 \mathrm{~s}$ at $Z_{0}=3.5$.

However, for further development of the compositions containing $\mathrm{Zr}$ and $\mathrm{ZrH}_{2}$, one should not seek only $I_{\mathrm{ef}}$ growth. The problem is not to increase the combustion temperature $T_{\mathrm{c}}$ very much, because if $T_{\mathrm{c}}$ is too high $(\geq 3800 \mathrm{~K})$, one should weight considerably the nozzle section with a heat shield. Tables 3 to 5 represent a part of data obtained with the most acceptable formulations for further investigations. In these tables, only formulations based on AP, ADN, and HMX oxidizers are included, because these oxidizers are rather developed while the others are not widely used in practice yet. All formulations in Tables 3 to 5 contain $20 \%$ (vol.) of binder. 
Analysis of the results shows that there is a considerable reserve to increase the ballistic effectiveness for engines with $Z_{0}=1.5-2.0$ (there are many missiles with such $Z_{0}$ values) only by replacing of $\mathrm{Al}$ with $\mathrm{Zr}$ or $\mathrm{ZrH}_{2}$.

All said above relates to a comparative analysis of the formulations based, on the one hand, on $\mathrm{Al}$ and, on the other hand, on $\mathrm{Zr}$ or $\mathrm{ZrH}_{2}$ with respect to their values of $I_{\text {ef }}$ and $T_{\mathrm{c}}$. However, the replacement of $\mathrm{Al}$ with $\mathrm{Zr}$ or $\mathrm{ZrH}_{2}$ can have other consequences, both positive and negative. Among possible negative consequences of such a replacement is the fact that $\mathrm{Zr}$ powder is rather pyrophoric, which may complicate propellant production and use. $\mathrm{ZrH}_{2}$ is less pyrophoric than $\mathrm{Zr}$ and, therefore, $\mathrm{ZrH}_{2}$ can be a good alternative to $\mathrm{Zr}$. Moreover, it was shown above that in many formulations, $\mathrm{ZrH}_{2}$ can create compositions with higher ballistic effectiveness than Zr. A considerably higher cost of $\mathrm{Zr}$ in comparison with $\mathrm{Al}$ is one of the serious barriers in using $\mathrm{Zr}$ in propellants, especially, in engines with large propellant volume.

Consider now the problem of the $I_{\mathrm{sp}}$ loss due to the presence of condensed phase in combustion products (that is, two-phase loss). Usually, the compositions with $20 \% \mathrm{Al}$ lose about $0.22 \% I_{\mathrm{sp}}$ per each $\mathrm{Al}$ percent. Surely, this value depends on the particle size (the smaller the solid particles, the less the loss level), specific heat (the higher the specific heat, the higher the $I_{\mathrm{sp}}$ loss), mass percentage of solid particles in combustion products (the higher the percentage, the higher the $I_{\mathrm{sp}}$ loss). Tables 3 to 5 show that the formulations with $46 \%-49 \% \mathrm{Zr}$ or $\mathrm{ZrH}_{2}$ (that is, with $60-65 \%$ (mass.) $\mathrm{ZrO}_{2}$ in combustion prod-

Table 3 The best formulations for engines with $Z_{0}$ values of 1.5 and $2.0(F=0.27$ and 0.54 )

\begin{tabular}{|c|c|c|c|c|c|c|c|c|c|}
\hline \multirow{3}{*}{ Formulation } & \multirow{3}{*}{$d$} & \multirow{2}{*}{\multicolumn{3}{|c|}{$\begin{array}{c}\text { Condensed } \\
\text { phase, } \%\end{array}$}} & \multirow{3}{*}{$I_{\mathrm{sp}}$} & \multicolumn{4}{|c|}{$Z_{0}$} \\
\hline & & & & & & \multicolumn{2}{|c|}{1.5} & \multicolumn{2}{|c|}{2.0} \\
\hline & & & mass & vol & & $I_{\mathrm{ef}}$ & $\Delta I_{\mathrm{ef}}$ & $I_{\mathrm{ef}}$ & $\Delta I_{\mathrm{ef}}$ \\
\hline $20 \% \mathrm{Al}+\mathrm{AP}+\mathrm{SHCB}$ & 1.847 & 3605 & 37 & 17.5 & 250.9 & 250.9 & 0.0 & - & 0.0 \\
\hline $46 \% \mathrm{Zr}+\mathrm{AP}+\mathrm{SHCB}$ & 2.571 & 3820 & 62.1 & 27.9 & 215.9 & 281.2 & 30.4 & 271.6 & 20.7 \\
\hline $43 \% \mathrm{Zr}+\mathrm{AP}+\mathrm{SHCB}$ & 2.494 & 3760 & 58.1 & 25.3 & 218.4 & - & - & 269.3 & 18.4 \\
\hline $46 \% \mathrm{Zr}+\mathrm{ADN}+\mathrm{SHCB}$ & 2.451 & 3690 & 62.1 & 26.6 & 224.7 & 282.0 & 31.1 & 273.8 & 22.9 \\
\hline $37 \% \mathrm{Zr}+\mathrm{AP}+\mathrm{AB}$ & 2.507 & 3804 & 50.0 & 21.9 & 212.0 & 270.8 & 19.9 & 262.3 & 11.4 \\
\hline $34 \% \mathrm{Zr}+\mathrm{ADN}+\mathrm{AB}$ & 2.322 & 3760 & 45.9 & 18.6 & 227.6 & 273.8 & 22.9 & 267.6 & 16.7 \\
\hline $37 \% \mathrm{Zr}+\mathrm{ADN}+\mathrm{AB}$ & 2.390 & 3844 & 50.0 & 20.9 & 225.1 & 277.0 & 26.1 & 269.6 & 18.7 \\
\hline $34 \% \mathrm{Zr}+\mathrm{HMX}+\mathrm{AB}$ & 2.411 & 3783 & 45.9 & 19.3 & 236.0 & 292.4 & 41.5 & 284.4 & 33.5 \\
\hline $37 \% \mathrm{Zr}+\mathrm{HMX}+\mathrm{AB}$ & 2.480 & 3830 & 50.0 & 21.6 & 233.3 & 295.6 & 44.7 & 286.6 & 35.7 \\
\hline $46 \% \mathrm{ZrH}_{2}+\mathrm{AP}+\mathrm{AB}$ & 2.654 & 3687 & 60.8 & 28.2 & 211.4 & 282.2 & 31.4 & 271.6 & 20.7 \\
\hline $49 \% \mathrm{ZrH}_{2}+\mathrm{AP}+\mathrm{AB}$ & 2.730 & 3707 & 64.8 & 30.9 & 209.2 & 285.4 & 34.5 & 273.8 & 22.9 \\
\hline $46 \% \mathrm{ZrH}_{2}+\mathrm{ADN}+\mathrm{AB}$ & 2.544 & 3632 & 60.8 & 27.0 & 220.7 & 285.1 & 34.3 & 275.7 & 24.8 \\
\hline $49 \% \mathrm{ZrH}_{2}+\mathrm{ADN}+\mathrm{AB}$ & 2.621 & 3646 & 64.8 & 29.6 & 218.0 & 288.3 & 37.4 & 277.9 & 27.0 \\
\hline $37 \% \mathrm{ZrH}_{2}+\mathrm{HMX}+\mathrm{AB}$ & 2.423 & 3340 & 48.9 & 20.7 & 229.7 & 285.7 & 34.8 & 277.7 & 26.8 \\
\hline
\end{tabular}


Table 4 The best formulations for engines with $Z_{0}$ values of 2.5 and $3.0(F=0.81$ and 1.08)

\begin{tabular}{|c|c|c|c|c|c|c|c|c|c|}
\hline \multirow{3}{*}{ Formulation } & \multirow{3}{*}{$d$} & \multicolumn{4}{|c|}{ Condensed } & \multicolumn{4}{|c|}{$Z_{0}$} \\
\hline & & \multirow[t]{2}{*}{$T_{\mathrm{c}}$} & \multicolumn{2}{|c|}{ phase, $\%$} & \multirow[t]{2}{*}{$I_{\mathrm{sp}}$} & \multicolumn{2}{|c|}{2.5} & \multicolumn{2}{|c|}{3.0} \\
\hline & & & mass & vol & & $I_{\mathrm{ef}}$ & $\Delta I_{\mathrm{ef}}$ & $I_{\text {ef }}$ & $\Delta I_{\mathrm{ef}}$ \\
\hline $20 \% \mathrm{Al}+\mathrm{AP}+\mathrm{SHCB}$ & 1.847 & 3605 & 37 & - & 250.9 & 250.9 & 0.0 & - & $\overline{0.0}$ \\
\hline $46 \% \mathrm{Zr}+\mathrm{AP}+\mathrm{SHCB}$ & 2.571 & 3820 & 62.1 & 27.9 & 215.9 & 265.6 & 14.7 & 261.5 & 10.6 \\
\hline $43 \% \mathrm{Zr}+\mathrm{AP}+\mathrm{SHCB}$ & 2.375 & 3662 & 62.1 & 25.7 & 228.4 & 267.9 & 17 & 264.7 & 13.8 \\
\hline $37 \% \mathrm{Zr}+\mathrm{ADN}+\mathrm{AB}$ & 2.390 & 3844 & 50.0 & 20.9 & 225.1 & 265 & 14.1 & 261.8 & 10.9 \\
\hline $34 \% \mathrm{Zr}+\mathrm{HMX}+\mathrm{AB}$ & 2.411 & 3783 & 45.9 & 19.3 & 236.0 & 279.3 & 28.4 & - & - \\
\hline $37 \% \mathrm{Zr}+\mathrm{HMX}+\mathrm{AB}$ & 2.480 & 3830 & 50.0 & 21.6 & 233.3 & 281 & 30.1 & 276.9 & 26.0 \\
\hline $49 \% \mathrm{ZrH}_{2}+\mathrm{AP}+\mathrm{AB}$ & 2.730 & 3707 & 64.8 & 30.9 & 209.2 & 265.1 & 14.2 & 261.9 & 11.0 \\
\hline $46 \% \mathrm{ZrH}_{2}+\mathrm{ADN}+\mathrm{AB}$ & 2.544 & 3632 & 60.8 & 27.0 & 220.7 & 269.8 & 18.9 & 265.8 & 14.9 \\
\hline $49 \% \mathrm{ZrH}_{2}+\mathrm{ADN}+\mathrm{AB}$ & 2.621 & 3646 & 64.8 & 29.6 & 218.0 & 271.4 & 20.5 & & \\
\hline $37 \% \mathrm{ZrH}_{2}+\mathrm{HMX}+\mathrm{AB}$ & 2.423 & 3340 & 48.9 & 20.7 & 229.7 & 272.7 & 21.8 & 269.2 & 18.3 \\
\hline
\end{tabular}

Table 5 The best formulations for engines with $Z_{0}$ values of $3.5(F=1.35$ and 1.08$)$

\begin{tabular}{|c|c|c|c|c|c|c|c|}
\hline \multirow[t]{2}{*}{ Formulation } & \multirow[t]{2}{*}{$d$} & \multirow[t]{2}{*}{$T_{\mathrm{c}}$} & \multicolumn{2}{|c|}{$\begin{array}{c}\text { Condensed } \\
\text { phase, } \%\end{array}$} & \multirow[t]{2}{*}{$I_{\mathrm{sp}}$} & \multicolumn{2}{|c|}{$Z_{0}=3.5$} \\
\hline & & & mass & vol & & $\overline{I_{\mathrm{ef}}}$ & $\Delta I_{\mathrm{ef}}$ \\
\hline $20 \% \mathrm{Al}+\mathrm{AP}+\mathrm{SHCB}$ & 1.847 & 3605 & 37 & 17.5 & 250.9 & - & 0.0 \\
\hline $43 \% \mathrm{Zr}+\mathrm{ADN}+\mathrm{SHCB}$ & 2.375 & 3662 & 62.1 & 25.7 & 228.4 & 262.3 & 11.4 \\
\hline $37 \% \mathrm{Zr}+\mathrm{ADN}+\mathrm{AB}$ & 2.390 & 3844 & 50.0 & 20.9 & 225.1 & 259.3 & 8.4 \\
\hline $37 \% \mathrm{Zr}+\mathrm{HMX}+\mathrm{AB}$ & 2.480 & 3830 & 50.0 & 21.6 & 233.3 & 274.1 & 23.2 \\
\hline $49 \% \mathrm{ZrH}_{2}+\mathrm{AP}+\mathrm{AB}$ & 2.730 & 3707 & 64.8 & 30.9 & 209.2 & 261.9 & 11.0 \\
\hline $46 \% \mathrm{ZrH}_{2}+\mathrm{ADN}+\mathrm{AB}$ & 2.544 & 3632 & 60.8 & 27.0 & 220.7 & 262.7 & 11.8 \\
\hline $37 \% \mathrm{ZrH}_{2}+\mathrm{HMX}+\mathrm{AB}$ & 2.423 & 3340 & 48.9 & 20.7 & 229.7 & 266.5 & 15.6 \\
\hline
\end{tabular}

ucts) exhibit the most optimal ballistic properties. Conventional compositions containing $20 \% \mathrm{Al}$ have $37 \%$ condensed $\mathrm{Al}_{2} \mathrm{O}_{3}$ in combustion products. As the specific heat of $\mathrm{ZrO}_{2}$ is more than twice lower $(0.49$ against $1.05 \mathrm{~J} /(\mathrm{g} \cdot \mathrm{K})$ ) than the specific heat of $\mathrm{Al}_{2} \mathrm{O}_{3}$, it can be estimated to the first approximation that in $\mathrm{Zr}$-containing compositions, the two-phase loss will be a bit less than in Alcontaining compositions (other conditions being equal, that is, if the particle size is the same).

There is another problem accompanying the replacement of $\mathrm{Al}$ with $\mathrm{Zr}$ or $\mathrm{ZrH}_{2}$. It is the possibility of slag formation during the combustion process. Usually, one does not increase $\mathrm{Al}$ percentage higher than $21 \%-22 \%$ in order not to achieve $\mathrm{Al}_{2} \mathrm{O}_{3}$ percentage of $38 \%-40 \%$ in combustion products; otherwise, some slag forms during the combustion. The compositions with $46 \%-49 \% \mathrm{Zr}$ or $\mathrm{ZrH}_{2}$ have higher mass percentage (a factor of 1.7) of solid metal oxide in combustion 
products than the compositions with $20 \% \mathrm{Al}$. However, because of higher $\mathrm{ZrO}_{2}$ density, the volume percentage of condensed metal oxides in combustion products is almost the same. As slag formation is the consequence of partial coagulation of metal and its oxide at initial combustion phase in the combustion chamber, the probability of slag formation in $\mathrm{Zr}$-containing compositions can be less than in Al-containing compositions because the melting point of $\mathrm{ZrO}_{2}$ is by $700-800 \mathrm{~K}$ higher than that of $\mathrm{Al}_{2} \mathrm{O}_{3}$.

A similar study of formulations with titanium and its hydride (instead of aluminum) has been carried out. It was shown that unlike the formulations with $\mathrm{Zr}$ and $\mathrm{ZrH}_{2}$, the formulations with $\mathrm{Ti}$ or $\mathrm{TiH}_{2}$ are not that promising because the densities of $\mathrm{Ti}\left(4.5 \mathrm{~g} / \mathrm{cm}^{3}\right)$ and $\mathrm{TiH}_{2}\left(3.9 \mathrm{~g} / \mathrm{cm}^{3}\right)$ are considerably less than those of $\mathrm{Zr}$ and $\mathrm{ZrH}_{2}$. Therefore, in the formulations with $\mathrm{Ti}$ and $\mathrm{TiH}_{2}$ (instead of $\mathrm{Al}$ ), the growth of propellant density does not compensate the loss of $I_{\mathrm{sp}}$.

\section{CONCLUDING REMARKS}

The replacement of aluminum with zirconium and its hydride in almost all solid composite propellants can increase the missile velocity for engines with the propellant volume-to-construction mass ratio less than 1.0-1.4 l/ kg.

The optimal ballistic effectiveness of propellants with zirconium or its hydride is attained at $35 \%-40 \% \mathrm{Zr}$ or $\mathrm{ZrH}_{2}$ in the formulation which is considerably higher than the optimal content of aluminum in the Al-containing compositions.

The compositions with $\mathrm{ZrH}_{2}$ are virtually equivalent to the compositions with individual $\mathrm{Zr}$. However, $\mathrm{ZrH}_{2}$ is better when used together with oxygen-rich oxidizers, while $\mathrm{Zr}$ is better when used with oxidizers containing less oxygen.

For all oxidizers under investigation (except HAP), the most optimal formulations are those with $\mathrm{Zr}$ or $\mathrm{ZrH}_{2}$ with an active binder.

\section{REFERENCES}

1. Trusov, B. G. 2002. 24th Symposium (International) on Chemical Thermodynamics Proceedings. St. Petersburg. 483.

2. Nechiporenko, G. N., and D.B. Lempert. 1998. An analysis of energy potentialities of composite solid propellants containing beryllium or beryllium hydride as an energetic component. Chem. Phys. Rep. 17(10):1927-47. 